\title{
Exploring Individual Change Readiness in a Chinese Context
}

\author{
Shuaijiao Bai ${ }^{1, a}, \mathrm{Pu} \mathrm{Li}^{1, \mathrm{~b}}$, Huiqin Zhang ${ }^{1, \mathrm{c}}$ \\ ${ }^{1}$ School of Management Science, Chengdu University of Technology, Chengdu, Sichuan, China \\ astrikebai@gmail.com, blipu_lipu@126@.com, c1056169292@qq.com
}

Keywords: organizational change, collective identities, military-civilian integration, perceived change readiness, Chinese context

\begin{abstract}
The current research tests the structure of individual change readiness (CR) and explores the relationships between employees' collective identities and individual $\mathrm{CR}$, in the context of Chinese military enterprises which have been implementing The Policy of Military-Civilian Integration. The results of the study 1 gives strong support to the argument that individual CR has two distinct components in terms of cognitive CR and affective CR. In research 2, the survey data were collected from 297 employees. The results of correlation analyses and hierarchical linear model show that civilian identity has positive effect on affective CR, but not on cognitive CR. Higher-hierarchy identity has significant positive effect on both cognitive CR and affective CR.
\end{abstract}

\section{Introduction}

Change readiness (abbr. CR) is a hot topic in both academic field and management practice [1-3] because it is believed as an important guarantee for successful organizational change through overcoming resistance to organizational change [4-7] and influencing commitment [8,9]. Although there are numerous researches on CR [2,10-17], there are still a few limitations in extant CR literatures. First, researchers recently argued that individual CR should have two dimensions including cognitive component and affective component [2]. However, no empirical research tested this argument directly. Therefore, the first purpose of this research is to test it directly.

Second, the antecedents of CR has attracted much attention in literature [2]. Social identity theory suggests that individual social identity plays great influence on their perceptions, attitudes, and behaviors $[18,19]$. However, no researches examine CR from identity theory perspective. Therefore, the second purpose is to explore how individual social identities influence his or her CR.

The current research will contribute to literature in three ways. First, it will provide direct empirical evidence to the two-component argument of CR, especially in the context of China. Second, taking the perspective of social identity will increase the understanding of CR. Third, most of existing CR researches were conducted in western countries. National cultures are different among nations and culture plays critical roles in individual perceptions and behavior [20,21]. Therefore, Chinese context will provide new evidences for understanding CR. At the same time, the findings will provide some useful practical suggestions for change managers.

\section{The research setting}

Chinese military enterprises which have been implementing The Policy of Military and Civilian Integration have been chosen as the research setting. International scholars may not be familiar with this context, and some hypotheses are embedded in the context tightly, so I briefly introduce the

\footnotetext{
${ }^{1}$ Shuaijiao BAI got his Ph.D from UESTC, and works for the School of Management Science, Chengdu University of Technology. His research interests include organizational change, organizational behavior, and human resources management. Phone:

+86-13541330321, Email: strikebai@gmail.com
} 
research setting here. This integration policy aims to achieve two goals simultaneously. One is to provide the military products quickly and efficiently to guarantee national security. The other is to maximize the use of resources to promote national economic development. Under this institutional context, all Chinese military enterprises have been forced to develop in both military and civilian market. The Chinese military market and civilian market have very different operational logics (see Table 1). In military system, good effect is the first goal sometimes the only one. Traditionally, planned system with rigorous planning and controlling provides a strong guarantee for this. While in civilian market system, pursuing efficiency and maximizing profit is the first goal. Market system with much flexibility provides strong guarantee [22]. Considering the pure military background, the implementing of this integration policy had brought great changes to both these enterprises and their employees. Therefore, this is a satisfactory context for our research question.

Table 1 Differences between military and civilian industry in China

\begin{tabular}{|c|c|c|}
\hline & Military & Civilian \\
\hline Market & $\begin{array}{ll}\cdot & \text { Planned system }\end{array}$ & $\begin{array}{ll}\cdot \quad \text { Market system } \\
\end{array}$ \\
\hline Most important interests & $\begin{array}{l}\text { - The interests of } \\
\text { the state and the } \\
\text { military }\end{array}$ & $\begin{array}{l}\text { - The interests of } \\
\text { customers and } \\
\text { suppliers }\end{array}$ \\
\hline Entry barriers & · $\quad$ Many & - $\quad$ Few \\
\hline Number of clients & $\begin{array}{l}\text { - Very limited } \\
\text { clients }\end{array}$ & $\begin{array}{l}\text { A large amount of } \\
\text { clients }\end{array}$ \\
\hline Competition & $\begin{array}{l}\text { - Very limited } \\
\text { competition }\end{array}$ & - $\quad$ Fierce competition \\
\hline Core competitive advantage & $\begin{array}{l}\text { - Relationships } \\
\text { with military and } \\
\text { relatively advanced } \\
\text { technology }\end{array}$ & $\begin{array}{l}\text { - Marketing, } \\
\text { production efficiency } \\
\text { and relatively advanced } \\
\text { technology }\end{array}$ \\
\hline
\end{tabular}

\section{Theory background and hypotheses}

\subsection{Individual change readiness}

There are different levels of CR such as individual, group, and organizational CR [2]. The current research addresses the individual CR which is reflected in organizational members' beliefs, attitudes and intentions regarding how urgent the change is needed, to what extent the organization is able to implement successfully, and one's emotional experience concerning the organizational change $[2,23,24]$. CR is regarded as the cognitive precursor to the attitude and behaviors [23]. The employee who has higher CR means that he or she will hold more positive attitudes, view the organization change as an urgent need, and think the organization is capable of implementing the change successfully. Individuals with higher level of CR will be expected to give the facing change more support than those with lower level of CR.

Rafferty et al. [2] gave a detailed literature review about the individual CR and suggested that individual perceived CR should have two distinct components in terms of cognitive CR and affective CR. Originally, Armenakis et al. [23] proposed that cognitive CR includes the belief about to what extent the specific change event is needed and the organization have sufficient capacity to implement the change. Then, Armenakis and Harris [1] extended this idea and described five beliefs underlying one's cognitive CR. While affective CR reflects an individual's positive emotions concerning the faced change event [2]. The root of affective CR is individual's current experience of a positive emotion and (or) an imaginary experiencing of some positive emotions in the future [2]. Although the above discussion explains the differences between cognitive CR and affective CR, there is a lack of empirical evidence. Therefore, we propose the first hypothesis. 
H1: Individual perceived CR consists of two distinct components, in terms of cognitive CR and affective CR.

\subsection{Identity theory}

Identity theories have the same fundamental assumption that the members of one social group may have similar perceptions and behaviors which are different from those of another social group [19]. Individuals have some special feeling and values for the sense of belonging to one social group [25]. In social identity theory [26-28], it is believed that actors take action which they think to best represent their own identities because they want to get self-verification through interactions between these behaviors and round environment. Therefore, each person has his or her own collective identities [29]. One collective identity is a kind of self-conception and self-awareness based on the social groups, aiming to define "who is I?" and "What action should I take? How should I act in this (or that) special social position ?" [30] between this group and other groups. One individual may have a few collective identities which may be emphasized separately in different situations. The salient collective identity will guide the individual's specific action in specific situation [31]. Therefore,

\subsection{Collective identities and perceived $C R$}

Group members tend to maintain a specific collective identity when social classification makes one group apparently different from other groups [32]. Members with the same collective identity will naturally tend to share the consciousness of this social classification within the same group but refuse to share with other groups [32]. Collective identities always mean specific goals, values, believes, norms, interaction styles and time range [33]. The hierarchy levels and departments are the dominating formal social categories within organizations [34] which strengthen these categories as salient classification to create different social groups. Hierarchical differentiation and other differentiation will shape different CR [3,23].

In relation to our research setting, we addressed two salient social groups. First, in Chinese military enterprises, the military and civilian departments is the most salient social groups. Each employee will be labeled as a military one or civilian one, not by their work places or uniforms but by the people's social consciousness. The members of the same department (e.g. volunteer sector) will have similar environment perceptions which are different from the perceptions of other groups (e.g. paid departments) [35]. Cognitive CR addresses the individual perceptions of change urgency and to what extent the change can be implemented successfully. The change is not these enterprises' choice but a have-to-and-must-task. And the focus of the change is how to develop civilian products. Chinese military enterprises usually have technological advantages. Combining the change context and connotation of cognitive CR together, I propose:

H2a: Individuals with civilian identity will have lower level of cognitive CR, comparing with those with military identity.

The implementing of integration policy means to develop civilian products by transferring some resources from military department to civilian department to strengthen its competitive advantage. In the process, the civilian department will benefit more from this change. Moreover, some employees who originally work as military workers may be transformed to civilian workers. For most of military workers, this kind of transformation means they will lost their military identity. But military identity is important symbolic label in Chinese context. Therefore, I propose:

H2b: Individuals with civilian identity will have higher level of affective CR, comparing with those with military-identity.

Second, hierarchy levels will form the second salient collective identities which put influence members' believes about organizational change [36]. Individuals at higher hierarchy level like top managers and board members have the abilities to influence the organizational policies $[37,38]$. The hierarchy levels influence organizational commitment, organizational identification and turnover intention [32] which are connected with perceived CR tightly. Higher hierarchy level means higher discretion [39] which often relates to higher CR [40]. The differences brought by hierarchies is more 
important in China than in western countries because of high power distance of Chinese culture [41]. For Chinese military enterprises, the integration change is initiated by top managers following the up-down direction. Many mobilizing activities which may take the form of political tasks are used to achieve agreement at higher hierarchy. Thus, we expect the hypothesis H3.

H3: Individuals with higher-hierarchy identity will have higher level of cognitive CR and affective CR.

\section{Study 1}

\subsection{The process}

The study 1 aimed to adapt the scale of CR and tested the hypothesis H1. Meanwhile, the improved scale will be used in study 2 to test the other hypotheses.

First, we adapted 6 items for cognitive CR and 3 items for affective CR from literature $[2,11,12,23,42,43]$, following the suggestions from Rafferty et al. [2]. Second, several discussions within the research team and with employees of the focused enterprises were conducted to assure that all the items were precise and easy enough to be understood. Third, we got 129 valid questionnaires from the total of 200 questionnaires, with the responding ration of $64.5 \%$, to test the hypothesis H1.

\subsection{Results and discussion}

The total sample was divided into two random sub samples. One was for exploratory factor analyses (EFA) and the other for confirmatory factor analysis. The results of EFA with principal components and varimax rotation showed that data were appropriate for EFA (KMO $>0.9$, Bartlett test $\left.\chi^{2}=4378.257, d f=378, \mathrm{P}<0.000\right)$. Two factors were emerged according to the eigenvalues greater than 1.00 . The cumulative variance was $69.312 \%$. The nine items had relatively high factor loadings (0.52-0.87) on expected factor. The CFA showed an acceptable goodness of fit $\left(\chi^{2}=58.01, d f=26\right.$, $N F I=0.93, N N F I=0.94, C F I=0.95, I F I=0.95, R F I=0.93, R M S E A=0.05)$ [44]. All items had the standardized loadings between 0.59 and 0.93 on expected factors. The Cronbach $\alpha$ was 0.92 for cognitive scale, and 0.82 for affective scale. These results provided strong support for the hypothesis $\mathrm{H} 1$ that individual CR has two distinct components.

\section{Study 2}

This study was designed to test the hypotheses H2a, H2b, and H3.

\subsection{The sample and process}

The data for this study were from 13 Chinese military enterprises through questionnaire survey. We emphasized the confidential promise at the instruction part of the questionnaire. The enterprises like the size, the sales, and the age of the enterprise etc. has been gotten from relevant managers. In total, we got 297 from 520 after excluding those contain missing data, with the valid ratio of 57.12\%. More detailed information about the sample is listed in Table 2.

\subsection{Measurement}

Individual $C R$. Both cognitive and affective CR were measured by using the scales described in the study 1 . The results of CFA showed good fitness $\left(\chi^{2}=62.31, d f=26, N F I=0.94, N N F I=0.96\right.$, $C F I=0.96, I F I=0.96, R F I=0.93$, RMSEA=0.05) [44]. The standardized loadings are between 0.56 and 0.90 . The two separate parts (Cronbach $\alpha=0.92$ and 0.90 separately) have good reliability.

Collective identities. Two dummy variables represent the focused two collective identities. One represents department difference, with 1 for civilian identity and 0 for military identity. The other represents higher-hierarchy identity, with 1 for top or middle managers department, 0 for production staff or lower managers.

Control variables. Sex (one dummy variable with 1 for male and 0 for female), education 
experience (how many years the respondent has been educated in schools), age, and tenure were controlled for at the individual level; organizational age (how many years since the organization's set up), size (how many employees in the organization), sale growth of last year, and economic development level (indicated by the GDP of the located city in last year) of its located city were also controlled for at the organization level.

\subsection{Results}

The descriptive analyses results are shown in Table 2. There is no significant correlation between affective CR and cognitive CR. This result supports H1. Civilian identity is positively correlated with affective CR ( $r=0.12, P<0.05$ ), which supports H2b; meanwhile, civilian identity is not significantly correlated with cognitive CR, hence H2a is not supported. Higher-hierarchy identity is positively and significantly correlated with affective CR $(r=0.16, P<0.01)$ and cognitive CR $(r=$ $0.15, P<0.05)$. This result gives support to H3. It is noticed that the correlation $(r=0.93, p<0.01)$ between age and tenure is too high. Therefore, one principle factor was generated and used to avoid possible influence on the validity of estimation in subsequent analyses.

Table 2 Descriptive statistics and correlation coefficients

\begin{tabular}{|c|c|c|c|c|c|c|c|c|c|c|c|c|c|}
\hline & Mean & S. D. & 1 & 2 & 3 & 4 & 5 & 6 & 7 & 8 & 9 & 10 & 11 \\
\hline 1.Sex & .71 & .46 & & & & & & & & & & & \\
\hline 2.Education & 17.30 & 1.33 & .11 & & & & & & & & & & \\
\hline 3.Age & 34.18 & 7.38 & $\begin{array}{l}.18^{*} \\
*\end{array}$ & -.08 & & & & & & & & & \\
\hline 4.Tenure & 11.37 & 8.51 & $\begin{array}{l}.15^{*} \\
*\end{array}$ & $-.24 * *$ & $.93 * *$ & & & & & & & & \\
\hline 5.Civilian identity & .37 & .48 & -.03 & $-.13^{*}$ & -.03 & -.02 & & & & & & & \\
\hline $\begin{array}{l}\text { 6.Higher-hierarchyide } \\
\text { ntity }\end{array}$ & .19 & .39 & $.15^{*}$ & .04 & $.47 * *$ & $.47 * *$ & -.06 & & & & & & \\
\hline 7.Cognitive CR & 4.17 & .90 & -.05 & .02 & $-.17 * *$ & $-.14^{*}$ & .10 & $.15^{*}$ & & & & & \\
\hline 8.Affective CR & 4.10 & 1.10 & .05 & $.15^{*}$ & .05 & .05 & $.12^{*}$ & $\begin{array}{l}.16^{*} \\
*\end{array}$ & $\begin{array}{l}\dot{0} \\
5\end{array}$ & & & & \\
\hline 9. Organizational age & 54.08 & 6.67 & -.08 & -.11 & -.08 & -.04 & $\begin{array}{l}-.12 \\
*\end{array}$ & .07 & $\begin{array}{l}\dot{1} \\
3 \\
*\end{array}$ & $\begin{array}{l}.0 \\
3\end{array}$ & & & \\
\hline 10.Organization size & $\begin{array}{l}6952 . \\
97\end{array}$ & $\begin{array}{l}6952 . \\
94\end{array}$ & -.01 & $-.22 * *$ & $.17 * *$ & $.19 * *$ & .03 & .02 & $\begin{array}{l}. \\
0 \\
4\end{array}$ & $\begin{array}{l}-.1 \\
4^{*}\end{array}$ & .16 & & \\
\hline 11.Sale growth & 33.30 & 66.94 & .00 & $-.33 * *$ & .03 & .08 & $\begin{array}{l}-.16 \\
* *\end{array}$ & .04 & $\begin{array}{l}- \\
0 \\
7\end{array}$ & $\begin{array}{l}-.1 \\
3 *\end{array}$ & $\begin{array}{l}-.25 \\
* *\end{array}$ & -.06 & \\
\hline $\begin{array}{l}\text { 12.Economy } \\
\text { development }\end{array}$ & $\begin{array}{l}44624 \\
.35\end{array}$ & $\begin{array}{l}22022 \\
.68\end{array}$ & -.04 & $.17 * *$ & $-.34 * *$ & $-.35 * *$ & $.13^{*}$ & -.10 & $\begin{array}{l}. \\
3 \\
7 \\
* \\
*\end{array}$ & $\begin{array}{l}.3 \\
3^{*} \\
*\end{array}$ & .10 & $\begin{array}{l}-.48 * \\
*\end{array}$ & $\begin{array}{l}-. \\
12 \\
*\end{array}$ \\
\hline
\end{tabular}

\section{Valid $\mathrm{N}=297$}

*. Correlation is significant at the 0.05 level (2-tailed).

**. Correlation is significant at the 0.01 level (2-tailed)

Considering the nested nature of the data, the Hierarchical Linear Modeling (HLM) was applied to test the hypotheses. All continuous variables were group centered. The results for both cognitive and affective CR are shown in Table 3. Civilian identity has significant effect on affective CR, but not on cognitive CR. This result supports the hypothesis H2b, but hypothesis H2a is not supported. Higher-hierarchy identity has positive effect on both affective CR and cognitive CR, which supports the hypothesis H3. 
Table 3 Results from Hierarchical Linear Model

\begin{tabular}{|c|c|c|c|c|c|}
\hline & \multirow[t]{2}{*}{ Dependent variables } & \multicolumn{2}{|c|}{ Cognitive CR } & \multicolumn{2}{|c|}{ Affective CR } \\
\hline & & M1a & M1b & M2a & M2b \\
\hline & Independent Variables & & & & \\
\hline & Civilian identity & & .10 & & $.13^{*}$ \\
\hline 2. & $\begin{array}{l}\text { Higher-Hierarchy identity } \\
\text { Individual Controls }\end{array}$ & & $.34 *$ & & $.40 *$ \\
\hline & Individual controls & -.04 & -.06 & .02 & -.00 \\
\hline & Education & .03 & .02 & $.12 \dagger$ & $.11 \dagger$ \\
\hline 5. & $\begin{array}{l}\text { Age_tenure factor } \\
\text { Organizational Controls }\end{array}$ & -.02 & -.08 & $.11 \dagger$ & .03 \\
\hline & Organizational age & .06 & .05 & -.00 & -.01 \\
\hline & Organization size & $.27 * * *$ & $.27 * * *$ & .01 & .01 \\
\hline & Sales growth & .03 & .03 & -.05 & -.04 \\
\hline & Economy development & $.50 * * *$ & $.48 * * *$ & $.34 * * *$ & $.33 * * *$ \\
\hline
\end{tabular}

Valid $\mathrm{N}=297 ; \dagger \mathrm{P}<0.1 ; * \mathrm{P}<0.05 ; * * \mathrm{P}<0.01 ; * * * \mathrm{P}<0.001$.

\section{Discussion and conclusion}

The findings can be summarized into two points. First, for the argument that individual CR should have two dimensions including cognitive component and affective component [2], the findings provide strong empirical evidence. Second, consistent with identity theory, the results showed that the collective identities do influence individuals' CR. Combining with the high mean and low standardized deviation of cognitive CR (mean=4.17, S.D. $=0.90$ ), the result that civilian identity does not has significant effect on cognitive CR shows that employees in Chinese enterprises do think that integration change is not avoidable and the change will be implemented well, no matter they are civilian workers or military workers.

The higher-hierarchy identity has significant effect on both kind of CR. One reason may be that the higher hierarchy members have more information about the change which the lower hierarchies may not obtain, as well as more resources and social network resources which are all beneficial to deal with possible difficulties during the process of change. One may also interpret like that the organizational change does bring turbulence and chaos which will give higher hierarchical managers more chances to get more (legal or illegal) benefit [45]. What is the fact depends on specific situation, which may be an interesting question for future research.

The reported results are consistent with the view that organizational change is a kind of meaning rather than a tangible thing. To what extent individuals hold cognitive and affective CR greatly depends on their own social identities. So, the view of rationalist that the organizational change is a completely rational process should be considered with doubt [46], and the idea of contingency of naturalist may be more reasonable.

Organizational change practitioners will get theoretic instructions from the findings. Based on the findings that social identities have significant effects on individual CR, the change managers can make more precise change tactics which can improve focused employees' $\mathrm{CR}$, and decrease their resistance to change. By doing so, the process of organizational change can be expected to be more successful, given the tight connection between perceived CR and behaviors [2,7].

The current research also had some limitations. First, this research is in the special research setting, future researches can test the results in different research settings. Second, I did not distinguish the underlying beliefs of CR [1], future research may explore the deep structure of cognitive CR and affective CR. Third, the dynamic property of perceived CR [47] has not been taken into consideration, future researches may explore whether the relationship between collective identities and CR vary between two change stages [48]. 


\section{References}

[1] Armenakis, A.A. and Harris, S.G. Crafting a change message to create transformational readiness[J]. Journal of Organizational Change Management, 2002,15(2):169-183.

[2] Rafferty, A.E., Jimmieson, N.L. and Armenakis, A.A. Change readiness: A multilevel review[J]. Journal of Management, 2013,39(1):110-135.

[3] Kuntz, J.R.C. and Gomes, J.F.S. Transformational change in organisations: A self-regulation approach[J]. Journal of Organizational Change Management, 2012,25(1):143-162.

[4] Elrod II, P.D. and Tippett, D.D. The “death valley” of change[J]. Journal of Organizational Change Management, 2002,15(3):273-291.

[5] Hammond, G.D., Gresch, E.B. and Vitale, D.C. Homegrown process improvement employing a change message model[J]. Journal of Organizational Change Management, 2011,24(4):487-510.

[6] Trader-Leigh, K.E. Case study: identifying resistance in managing change[J]. Journal of Organizational Change Management, 2002,15(2):138-155.

[7] Self, D.R. Organizational change-overcoming resistance by creating readiness[J]. Development and Learning in Organizations, 2007,21(5):11-13.

[8] Ansari, N.G. Employee Perception of HRM Practices: Impact on Commitment to the Organization.[J]. South Asian Journal of Management, 2011,18(3):122-149.

[9] Österberg, P. and Nilsson, J. Members' perception of their participation in the governance of cooperatives: The key to trust and commitment in agricultural cooperatives[J]. Agribusiness, 2009,25(2):181-197.

[10]Bouckenooghe, D., Devos, G. and Van den Broeck, H. Organizational change questionnaireclimate of change, processes, and readiness: Development of a new instrument[J]. The Journal of Psychology, 2009,143(6):559-599.

[11]Castañeda, S.F., Holscher, J., Mumman, M.K., Salgado, H., Keir, K.B., Foster-Fishman, P.G. and Talavera, G.A. Dimensions of community and organizational readiness for change[J]. Progress in Community Health Partnerships: Research, Education, and Action, 2012,6(2):219-226.

[12] Cinite, I., Duxbury, L.E. and Higgins, C. Measurement of perceived organizational readiness for change in the public sector[J]. British Journal of Management, 2009,20(2):265-277.

[13]Hicks, R. and McCracken, J. Readiness for change.[J]. Physician Executive Journal, 2011,January-February82-84.

[14]Holt, D.T., Armenakis, A.A., Feild, H.S. and Harris, S.G. Readiness for organizational change: The systematic development of a scale[J]. The Journal of Applied Behavioral Science, 2007,43(2):232-255.

[15]Kim, T.G., Hornung, S. and Rousseau, D.M. Change-supportive employee behavior: Antecedents and the moderating role of time[J]. Journal of Management, 2011,37(6):1664-1693.

[16] Timmor, Y. and Zif, J. Change readiness: an alternative conceptualization and an exploratory investigation[J]. EuroMed Journal of Business, 2010,5(2):138-165.

[17]Weiner, B.J. A theory of organizational readiness for change[J]. Implementation Science, 2009,4(1):67. 
[18]Hogg, M.A. Social identity theory. In: Burke, P., ed. Contemporary Social Psychological Theories. Stanford, California: Stanford University Press, 2006:111-135.

[19]Ellemers, N., Spears, R. and Doosje, B. Self and social identity[J]. Annual Review of Psychology, 2002,53161-186.

[20]Schein, E.H. Three cultures of management: The key to organizational learning[J]. Glocal working. Living and working across the world with cultural intelligence, 201037.

[21] Schein, E.H. Culture as an environmental context for careers[J]. Journal of Organizational Behavior, 2007,5(1):71-81.

[22]Thomas, J.B., Clark, S.M. and Gioia, D.A. Strategic sensemaking and organizational performance: Linkages among scanning, interpretation, action, and outcomes[J]. Academy of Management Journal, 1993,36(2):239-270.

[23] Armenakis, A.A., Harris, S.G. and Mossholder, K.W. Creating readiness for organizational change[J]. Human Relations, 1993,46(6):681-703.

[24]Eby, L.T., Adams, D.M., Russell, J.E.A. and Gaby, S.H. Perceptions of organizational readiness for change: Factors related to employees' reactions to the implementation of team-based selling[J]. Human Relations, 2000,53(3):419-442.

[25]Tajfel, H. Social identity and intergroup behaviour.[J]. Social Science Information/sur les sciences sociales, 1974,13(2):65-93.

[26] Abrams, D. and Hogg, M.A. Social Identity and Social Cognition[M]. Oxford: Wiley-Blackwell, 1999.

[27]Baumeister, R. Identity[M]. New York: Oxford University Press, 1986.

[28]Fletcher, J.B. A Revised Theory of Cognitive Consistency. Oakland: University of California, 2010.

[29]Sedikides, C. and Brewer, M.B. Individual Self, Relational Self, Collective Self[M]. Philadelphia: Psychology Press, 2001.

[30]McCall, G.J. and Simmons, J.L. Identities and Interactions.[M]. New York, US: Free Press, 1966.

[31] Turner, J.C. Theory, The Structure Of Sociological[M]. Belmon, CA: Wadsworth Publishing Company, 2002.

[32]Cole, M.S. and Bruch, H. Organizational identity strength, identification, and commitment and their relationships to turnover intention: Does organizational hierarchy matter?[J]. Journal of Organizational Behavior, 2006,27(5):585-605.

[33] Ashforth, B.E. Role Transitions in Organizational Life: An Identity-based Perspective[M]. Mahwah, NJ: Lawrence Erlbaum, 2001.

[34]Mintzberg, H. Power in and around organizations[M]. Englewood Cliffs, New Jersey: Prentice-Hall, 1983.

[35]Kreutzer, K. and Jäger, U. Volunteering versus managerialism: Conflict over organizational identity in voluntary associations[J]. Nonprofit and Voluntary Sector Quarterly, 2011,40(4):634-661. 
[36] Corley, K.G. Defined by our strategy or our culture? Hierarchical differences in perceptions of organizational identity and change[J]. Human Relations, 2004,57(9):1145-1177.

[37]Glynn, M.A. When cymbals become symbols: Conflict over organizational identity within a symphony orchestra[J]. Organization Science, 2000,11(3):285-298.

[38]Scott, S.G. and Lane, V.R. A stakeholder approach to organizational identity[J]. Academy of Management Review, 2000,25(1):43-62.

[39] Hambrick, D.C. and Mason, P.A. Upper echelons: The organization as a reflection of its top managers[J]. Academy of Management Review, 1984,9(2):193-206.

[40]Miller, D., Madsen, S.R. and John, C. Readiness for change: Implications on employees' relationship with management, job knowledge and skills, and job demands[J]. Journal of Applied Management and Entrepreneurship, 2006,11(1):3-16.

[41]Hofstede, G., Hofstede, G.J. and Minkov, M. Cultures and Organizations[M].: McGraw Hill New York, NY, 1997.

[42] Greenwood, R. and Hinings, C.R. Understanding radical organizational change: Bringing together the old and the new institutionalism[J]. Academy of Management Review, 1996,21(4):1022-1054.

[43]Choi, M. and Ruona, W.E. Individual readiness for organizational change and its implications for human resource and organization development[J]. Human Resource Development Review, 2011,10(1):46-73.

[44] Hu, L. and Bentler, P.M. Cutoff criteria for fit indexes in covariance structure analysis: Conventional criteria versus new alternatives[J]. Structural Equation Modeling: A Multidisciplinary Journal, 1999,6(1):1-55.

[45]Galperin, B.L., Bennett, R.J. and Aquino, K. Status differentiation and the protean self: A social-cognitive model of unethical behavior in organizations[J]. Journal of Business Ethics, 2011,98(3):407-424.

[46]Mills, J.H., Dye, K. and Mills, A.J. Understanding Organizational Change[M]. New York: Taylor \& Francis, 2008.

[47]Cunningham, C.E., Woodward, C.A., Shannon, H.S., MacIntosh, J., Lendrum, B., Rosenbloom, D. and Brown, J. Readiness for organizational change: A longitudinal study of workplace, psychological and behavioural correlates[J]. Journal of Occupational and Organizational Psychology, 2002,75(4):377-392.

[48]Lewin, K. Frontiers in group dynamics: Concept, method and reality in social science; social equilibria and social change[J]. Human Relations, 2010,1(1):5-41. 